\title{
FoxP2 Expression in Avian Vocal Learners and Non-Learners
}

\author{
Sebastian Haesler, ${ }^{1 \star}$ Kazuhiro Wada, ${ }^{2 \star}$ A. Nshdejan, ${ }^{1}$ Edward E. Morrisey, ${ }^{4}$ Thierry Lints, ${ }^{3}$ Eric D. Jarvis, ${ }^{2}$ and \\ Constance Scharff ${ }^{1}$ \\ ${ }^{1}$ Max-Planck Institute for Molecular Genetics, 14195 Berlin, Germany, ${ }^{2}$ Department of Neurobiology, Duke University Medical Center, Durham, North \\ Carolina 27710, ${ }^{3}$ City College of City University of New York, New York, New York 10031, and ${ }^{4}$ University of Pennsylvania, Philadelphia, Pennsylvania \\ 19104
}

Most vertebrates communicate acoustically, but few, among them humans, dolphins and whales, bats, and three orders of birds, learn this trait. FOXP2 is the first gene linked to human speech and has been the target of positive selection during recent primate evolution. To test whether the expression pattern of FOXP2 is consistent with a role in learned vocal communication, we cloned zebra finch FoxP2 and its close relative FoxP1 and compared $\mathrm{mRNA}$ and protein distribution in developing and adult brains of a variety of avian vocal learners and non-learners, and a crocodile. We found that the protein sequence of zebra finch FoxP2 is 98\% identical with mouse and human F0XP2. In the avian and crocodilian forebrain, FoxP2 was expressed predominantly in the striatum, a basal ganglia brain region affected in patients with FOXP2 mutations. Strikingly, in zebra finches, the striatal nucleus Area X, necessary for vocal learning, expressed more FoxP2 than the surrounding tissue at post-hatch days 35 and 50, when vocal learning occurs. In adult canaries, FoxP2 expression in Area $\mathrm{X}$ differed seasonally; more FoxP2 expression was associated with times when song becomes unstable. In adult chickadees, strawberry finches, song sparrows, and Bengalese finches, Area X expressed FoxP2 to different degrees. Non-telencephalic regions in both vocal learning and non-learning birds, and in crocodiles, were less variable in expression and comparable with regions that express FOXP2 in human and rodent brains. We conclude that differential expression of FoxP2 in avian vocal learners might be associated with vocal plasticity.

Key words: language; winged-helix/forkhead box; transcription factor; songbird; hummingbird; parrot; ring dove

\section{Introduction}

Human speech and birdsong share behavioral and neural similarities (Doupe and Kuhl, 1999; Brainard and Doupe, 2002; Wilbrecht and Nottebohm, 2003; Jarvis 2004). Both are learned during a critical period via the interaction of auditory and motor centers and require specialized cerebral structures, which are functionally lateralized (Bottjer and Arnold, 1985). Whereas innate dispositions to learn and produce species-appropriate sounds are present in both humans and birds (Pinker, 1994; Doupe and Kuhl, 1999), mutations that predominantly affect vocal communication seem rare (Fisher et al., 2003). The only gene identified is FOXP2, the mutated form of which has been autosomal-dominantly inherited through three generations by approximately half of the family members of the KE family (Lai et al., 2001). Affected family members have difficulty with the cor-

Received Sept. 25, 2003; revised Feb. 10, 2004; accepted Feb. 10, 2004.

This work was supported by National Science Foundation Grant IBN0084357 to E.D.J. and a Sonderforschungsbereich 515 grant to C.S. We are indebted to Patricia Nierle for her initial participation in this project, and we thank the Ropers, Nuber, Scherthahn, Vortkamp, Antebi, Tchenichovski, and Brinkmann laboratories for sharing thoughts and resources and Luis Puelles, Onur Günktürkün, and Barbara Nixdorf for discussion. We also thank Dr. Hironobu Sakaguchi for birds, Daphne Soares for the crocodile brains, and Deepa Sambandan, Sophie Scotto-Lomassese, Katrin Guse, Lydia Nagler, Sebastian Marquard, and Martin Begemann for experimental support.

*S.H. and K.W. contributed equally to this work.

Correspondence should be addressed to either of the following: Dr. C. Scharff, Max-Planck Institute for Molecular Genetics, Ihnestrasse 73, 14195 Berlin, Germany, E-mail: scharff@molgen.mpg.de; or Dr. E. D. Jarvis, Department of Neurobiology, Duke University Medical Center, Box 3209, Durham, NC 27710, E-mail: jarvis@neuro.duke.edu.

DOI:10.1523/JNEUROSCI.4369-03.2004

Copyright (C) 2004 Society for Neuroscience $\quad 0270-6474 / 04 / 243164-12 \$ 15.00 / 0$ rect articulation of speech and score lower in receptive and grammatical language tests than their unaffected relatives. Execution of sequenced orofacial movements is also impaired (for review, see Fisher et al., 2003; Marcus and Fisher, 2003). In contrast, nonverbal cognitive abilities differ less dramatically between individuals with or without FOXP2 mutations (Vargha-Khadem et al., 1995; Watkins et al., 2002).

FOXP2 belongs to the large winged-helix/forkhead box (Fox) transcription factor gene family (Kaestner et al., 2000), originally identified in Drosophila (for review, see Kaufmann and Knochel, 1996). Forkhead genes play pivotal roles in development and adulthood (Carlsson and Mahlapuu, 2002). In mammals, three of the four FoxP family members were originally isolated from mouse lung, where Foxp1 and Foxp2 act as transcriptional repressors (Shu et al., 2001; Lu et al., 2002). Analysis of FOXP2 molecular evolution suggests that this gene has been the target of positive selection during recent primate evolution (Enard et al., 2002).

Although it remains to be shown how FOXP2 acts in the brain, rapid progress has been made in demonstrating where FOXP2 acts. Structural and functional brain anomalies of affected individuals carrying FOXP2 mutations implicate the basal ganglia as a key affected brain region (Watkins et al., 1999; Belton et al., 2003). The striatum, a component of the basal ganglia, is also the site of high FOXP2 expression in the developing human and rodent brain (Ferland et al., 2003; Lai et al., 2003; Takahashi et al., 2003). Because vocal learning in songbirds depends on a special- 
ized pathway through the basal ganglia, including the striatal vocal nucleus, Area X (Sohrabji et al., 1990; Scharff and Nottebohm, 1991), we asked: (1) Do birds that learn to vocalize differ in FoxP2 brain expression patterns from birds that vocalize innately? (2) How do brain expression patterns of avian FoxP2 and its close homolog FoxP1 compare with expression patterns in mammals, and how might these relate to the evolution of vocal learning? and (3) How similar is the amino acid sequence of FoxP2 protein in vocal learners (human, zebra finch) compared with a non-learner (mouse)? To address these questions, we cloned the FoxP2 and FoxP1 genes of a commonly studied vocal learner, the zebra finch, and used it as a probe to evaluate expression patterns in the brains of eight species of avian "vocal learners," two species of "vocal non-learners," and a crocodilian, the closest living non-avian relative (Meyer and Zardoya, 2003), presumably also a vocal non-learner.

\section{Materials and Methods}

Nomenclature. For avian brain regions, we used the recently revised nomenclature proposed by the Avian Brain Nomenclature Forum (Reiner et al., 2004b) (http://avianbrain.org/). For FoxP2 nomenclature, we followed the convention proposed by the Nomenclature Committee for the forkhead family of genes (i.e., FOXP2 in Homo, Foxp2 in Mus, and FoxP2 in all other species, proteins in roman type, and genes and RNA in italics) (Kaestner et al., 2000).

Species. We studied 11 avian species, ordered genetically relative to zebra finch: songbirds: zebra finches (Taeniopygia guttata), Bengalese finches (Lonchura Striata domestica), strawberry finches (Amandava amandava), song sparrows (Melospiza melodia), canaries (Serinus canaria), and black-capped chickadees (Phoecile atriacapillus); dove: ring doves (Streptopelia risoria); hummingbirds: rufous-breasted hermit (Glaucis hirsuta) and somber hummingbird (Aphantochroa cirrochloris); parrot/budgerigars (Melospiticus undulatus); and chicken: domestic chicken (Gallus gallus). Relationships were assessed from DNA-DNA hybridization melting temperature half-life indices (T50) and general taxonomy in the literature (Sibley and Ahlquist, 1990; Zann, 1996; Wada et al., 2004). The zebra, Bengalese, and strawberry finches all belong to three closely related subfamilies: Poephilini, Lonchurini, and Estrilini, respectively, of the Estrinidae family of birds. The song sparrow is a close relative belonging to the Passeridae family (T50 $=8.5$ removed), followed by the canary belonging to Fringillidae (T50 $=10.0$ removed), then black-capped chickadee belonging to Paridae (T50 $=11.1$ removed). Doves are the closest non-songbird relative examined (T50 = 21.6 removed), followed by hummingbirds, with the somber hummingbird and rufous-breasted hermit being two ancient species belonging to the only two family lineages Trochilidae and Phaethornithinae, respectively (Jarvis et al., 2000) (each T50 $=\sim 22.5$ removed), followed by parrots $(\mathrm{T} 50=23.1$ removed $)$, and finally by chicken being the most distant from songbirds (T50 $=28$ removed) (Sibley and Ahlquist, 1990). A crocodile (Alligator mississippiensis) was chosen as the closest living relative of birds (Meyer and Zardoya, 2003) for comparison.

Zebra finches were obtained from breeding colonies kept at Duke University, Tokyo Medical and Dental University, the Max-Planck Institute for Molecular Genetics Berlin, and City College of New York. Some birds were isolated $\sim 12 \mathrm{hr}$ overnight, followed by $1-2 \mathrm{hr}$ silent conditions in the morning with the lights on. When necessary, singing attempts were interrupted by human approach to examine FoxP2 expression in the absence of singing behavior. Brain sections from zebra finches that had sung a known quantity of undirected songs before perfusion and quiet controls and canaries that sang at different seasons of the year, song sparrows, hummingbirds, and parrots were obtained from the Jarvis laboratory collection (Jarvis et al., 1997; Jarvis and Nottebohm, 1997; Jarvis and Mello, 2000; Jarvis et al., 2000). For the seasonal canary experiment, we used $10 \mu \mathrm{m}$ cryostat-cut sections of brains of adult (20-32 months old) male canaries that were killed monthly between April 1995 and March 1996 (Jarvis and Nottebohm, 1997; Holzenberger et al., 1997). Song behavior [whether singing occurred, what type of singing (stereotyped or plastic), and how much singing] of each bird was scored and recorded $1 \mathrm{hr}$ before sacrifice. Quiet control black-capped chickadee brain sections were obtained from Dr. Tom Smulders (Jarvis laboratory) and Dr. David Sherry (University of Western Ontario, Ontario, Canada). Strawberry finches and additional canaries were purchased from a Tokyo breeder. Crocodile brain sections were obtained as part of another study by E.D.J. and K.W. in collaboration with Daphne Soares (University of Maryland). All animals were treated under the humane guidelines of the institutes where animals were bred and kept.

Cloning of FoxP2 and FoxP1 cDNAs from zebra finch brain. Primers specific for the mouse Foxp2 sequence were used to amplify zebra finch FoxP2 from adult male zebra finch brain total RNA. We obtained a fragment covering bp 114-959 of isoform III, relative to first start codon, with primers 5'-GACACCAGCTCTGAAGTAAGCACA-3' and 5' -GGTAGTCGAGGAGGAATTGTTAGT-3' and the entire FoxP2 ORF with primers $5^{\prime}$ ATGATGCAGGAATCTGCGACA- $3^{\prime}$ and $5^{\prime}$-TCATTCCAGATCTTCAGATAAAG- $3^{\prime}$. A $180 \mathrm{bp}$ FoxP1 fragment was obtained using degenerated primers 5'-GARTTYTAYAARAAYGCNGANGT-3' and 5'-ATTRTGNCGNACNGCRTTYTTCC-3'. All PCR products were examined on agarose gels, cleaned from nucleotides with the Qiaquick PCR purification kit (Qiagen, Chatsworth, CA) and cloned into the pGEMTeasy vector (Promega, Madison, WI). Inserts from 15 independent FoxP2 clones and 6 FoxP1 clones were then sequenced on both strands. We obtained additional cDNA and, thus, sequence for each gene using the SMART-RACE kit (Clontech, Palo Alto, CA). Sequence assembly and analysis was done with GCG 10.1 (Accelrys, Cambridge, UK) and the Staden package (Staden et al., 1998). All sequences were deposited into GenBank (accession numbers AY549148, AY549149, AY549150, AY549151, and AY54952) and the songbird cDNA database (http://www.dbsr.duke.edu/songbird). One full ORF FoxP2 clone and one containing the fragment covering bp 114-959, relative to the first start codon, as well as the $180 \mathrm{bp}$ FoxP1 clone, were selected for the generation of riboprobes.

In situ hybridization and quantification. In situ hybridizations were performed according to two protocols using ${ }^{33} \mathrm{P}$-labeled (Vortkamp et al., 1996) or ${ }^{35}$ S-labeled (Mello et al., 1997) riboprobes. Both protocols yielded identical labeling patterns in the brain. Riboprobes were in vitro transcribed from T7 and SP6 promoter sides of the pGEMTeasy cloning vector containing the FoxP2 and FoxP1 cDNA clones. Slides were exposed to $\mathrm{x}$-ray film (Bio-max; Eastman Kodak, Rochester, NY) for 2-3 d $\left({ }^{35} \mathrm{~S}\right.$-labeled material) or $1-3 \mathrm{~d}\left({ }^{33} \mathrm{P}\right)$. For species comparison and developmental studies, a set of 163 slides with sections from 11 different species and from zebra finches of 12 different developmental ages [embryonic stages $10,23,26$, and 28 and featherbud stage embryos corresponding approximately to chick stages 34 and 37, and post-hatch days (PHDs) 15, 25, 35, 45, and 75 and adults $>90 \mathrm{~d}$ ] were hybridized at the same time with a FoxP2 mastermix, with the same counts per minuteradioactive count per slide. For the seasonal comparisons, all sections were also hybridized with a master mix. FoxP1 was hybridized on another day to avoid the possibility of cross-contamination. For in situ quantifications, the exposed film was placed under a high-power dissecting scope (Wild M420; Leica, Deerfield, IL) and scanned into a computer using a Spot III camera and Spot software version 3.2.4 (Diagnostic Instruments, Sterling Heights, MI). Images were transferred to Photoshop (Adobe, San Jose, CA) and converted to grayscale. Vocal nuclei and adjacent non-vocal areas, i.e., the surrounding brain subdivisions (caudal nidopallium ventrally adjacent to HVC; nonauditory arcopallium abutting the robust nucleus of the arcopallium (RA); nidopallium rostral to lateral magnocellular nucleus of the anterior nidopallium (IMAN) and the surrounding shell region; caudal striatum (CSt) immediately caudal to Area $\mathrm{X}$ ) were outlined with a selection tool, and the average pixel density was calculated using the Photoshop histogram function.

To calculate ratios of differential expression in vocal nuclei relative to their surrounding brain subdivision, we divided the pixel density values of vocal regions by the pixel density values of the respective adjacent region, using comparably sized areas for quantification. When expression within a given vocal nucleus is the same as the expression of the region surrounding it, the ratio is 1 ; when the expression within the vocal nucleus is higher than expression in the region surrounding it, the ratio is $>1$; when lower, the ratio is $<1$. 
Preparation of brain sections. Serial sagittal or frontal sections were cut either frozen on a rotary cryostat $(8 \mu \mathrm{m}$ or $10 \mu \mathrm{m})$, paraffin embedded and cut on a rotary microtome $(8 \mu \mathrm{m})$, or paraformaldehyde perfused and cut on a vibratome $(40 \mu \mathrm{m})$. Before embedding in paraffin, the brains were immersed in Serra's fixative $(60 \% \mathrm{EtOH}, 30 \%$ concentrated formaldehyde, and $10 \%$ acetic acid). The paraffin-embedded and the fresh-frozen brain sections postfixed in $4 \%$ paraformaldehyde were used for in situ hybridizations (ISH). The fresh-frozen sections (slide mounted) or free-floating vibratome sections were used for immunohistochemistry (IHC).

Northern blotting. Twenty micrograms of total RNA from adult male zebra finch brain and lung were separated on a $1 \%$ denaturing agarose gel and blotted onto a nylon membrane (Amersham Biosciences, Piscataway, NJ) overnight. The membrane was then incubated with a ${ }^{32} \mathrm{P}$ labeled FoxP2 fragment spanning bp 114-959 relative to the first start codon of isoform III at $65^{\circ} \mathrm{C}$ for $3 \mathrm{hr}$. The blot was washed and exposed to an MS-intensifying screen (Eastman Kodak), which was then scanned with a PhosphorImager (Molecular Dynamics, Sunnyvale, CA) and analyzed with ImageQuant software 5.2 (Molecular Dynamics).

Western Blotting. Brains from PHD 40 male zebra finches were crushed in liquid nitrogen and then lysed in hypotonic lysis buffer containing $0.1 \% \mathrm{NP}-40$ for $10 \mathrm{~min}$. Extracts were then centrifuged for $10 \mathrm{~min}$ at $1500 \times g$, and the resulting pellet was dissolved in Laemmli buffer and denatured for $5 \mathrm{~min}$ at $95^{\circ} \mathrm{C}$. Nuclear extracts were separated by SDSPAGE (8\%), transferred to a polyvinylidene fluoride membrane (Roche, Indianapolis, IN), and blocked with $1 \%$ BSA in PBS/0.1\%Tween 20 for 1 hr. The membranes were then incubated with a rabbit polyclonal Foxp2 antibody [1:150 dilution; raised against aa 613-715 of mouse Foxp2 and immunopurified against Foxp1 protein (Lu et al., 2002)] for $1 \mathrm{hr}$, followed by incubation with an HRP-conjugated anti-rabbit antibody (1: 2000 dilution; Amersham Biosciences) for another $30 \mathrm{~min}$. Binding was detected on $\mathrm{x}$-ray films using an ECL detection system for HRP (PerkinElmer, Boston, MA).

Immunohistochemistry. In addition to the Foxp2 antibody described above, we used the following primary antibodies in double-labeling experiments, recognizing: human neuronal protein $\mathrm{HuC} / \mathrm{D}$ (monoclonal; Molecular Probes, Eugene, OR), cAMP-regulated phosphoprotein of molecular weight 32,000 (DARPP-32; polyclonal; Santa Cruz Biotechnology, Santa Cruz, CA), polysialylated neural cell adhesion molecule (PSA-NCAM; monoclonal; AbCys, Paris, France), tyrosine hydroxylase (TH; polyclonal; Santa Cruz Biotechnology), parvalbumin (monoclonal; Swant, Bellinzona, Switzerland), anti-nitric oxide synthase (rabbit polyclonal; Zymed, San Francisco, CA), calbindin (rabbit polyclonal; Swant), and ChAT (polyclonal; Chemicon, Temecula, CA). Paraformaldehyde (4\%)-perfused tissue was washed three or more times in $0.1 \mathrm{M}$ phosphate buffer $(\mathrm{PB})$ and preincubated for a minimum of $30 \mathrm{~min}$ with a permeabilization/blocking buffer $(0.1 \mathrm{M} \mathrm{PB}, 2 \%$ skim milk, and $0.3 \%$ Triton $\mathrm{X}-100$ ), followed by incubations with primary antibodies either for $1 \mathrm{hr}$ at room temperature or for $24-72 \mathrm{hr}$ at $4^{\circ} \mathrm{C}$. Secondary antibodies were either fluorescently labeled (FITC, Cy3, Cy5) or biotinylated. Biotinylated antibodies were reacted with $\mathrm{ABC}$ (Vector Laboratories, Burlingame, $\mathrm{CA}$ ) and visualized with DAB or DAB/cobalt (SigmaFast; Sigma, St. Louis, MO) reaction. Double labeling was performed using two different fluorescent secondary antibodies or using DAB to reveal one antigen and $\mathrm{DAB}$ with nickel enhancement for the second antigen. The double labeling was done sequentially unless the primary antibodies were raised in different species. To control for nonspecific binding of the secondary antibodies, control reactions were performed that included all steps, except incubation with the primary antibody.

\section{Results}

\section{Cloning of zebra finch FoxP2 and FoxP1}

We initially amplified an $845 \mathrm{bp}$ fragment of zebra finch FoxP2 ( $z$ fFoxP2) from adult male zebra finch brain cDNA using primers designed from the mouse Foxp2 ( $m$ Foxp2) sequence (see Material and Methods). With subsequent 5' and 3' RACE (Rapid Amplification of cDNA Ends), we assembled 2830 bp of zfFoxP2 mRNA that included $296 \mathrm{bp}$ of the $5^{\prime}$ untranslated region (UTR), the entire ORF of $2207 \mathrm{bp}$, and $327 \mathrm{bp}$ of the 3' UTR (GenBank accession numbers AY549148, AY549149, AY549150, and AY549151). To further confirm the zfFoxP2 sequence, we sequenced 12 independent clones carrying the entire ORF amplified from adult male zebra finch brain cDNA. We found that two DNA segments, which we called splice1 (71 bp) and splice2 (60 bp), were either present or absent in these clones, suggesting the existence of four $z f F o x P 2 \mathrm{mRNA}$ isoforms, each different at the $5^{\prime}$ end of the gene (Fig. 1A). Splicel introduces a stop codon at position 261 (relative to the first start codon), resulting in predicted protein isoforms III or IV that miss the first 92 amino acids. In human but not mouse, the splice1 fragment also exists (Bruce and Margolis, 2002). Splice2 introduces 20 additional amino acids in-frame into the predicted protein isoforms I and III. When the splice 2 fragment is absent, it results in isoforms II and IV. In human and mouse, splice2 is apparently never spliced out. Reverse transcription (RT)-PCR with RNA from a variety of zebra finch tissues using primers at both ends of the alternatively spliced region generated products that matched the sizes expected for the isoforms (Fig. $1 B, C$ ). There were, however, differences between tissues, with isoform IV being predominant in muscle, II-IV in lung, and all four in brain and liver (Fig. 1C). Northern hybridization on adult zebra finch brain and lung total RNA revealed four transcripts of $\sim 9.0,6.5,3.5$, and $2.5 \mathrm{~kb}$, respectively (Fig. $1 D$ ). The 9.0, 3.5, and $2.5 \mathrm{~kb}$ transcripts corresponded in size to the transcripts found in mouse (Shu et al., 2001), whereas the $6.5 \mathrm{~kb}$ transcript matched the size of the human transcript (Lai et al., 2001). The size of the two most abundant $z$ fFoxP2 transcripts of 9.0 and $6.5 \mathrm{~kb}$ suggests that they contain large amounts of regulatory sequence, perhaps to precisely regulate $z f F o x P 2$ translation, mRNA location, and mRNA stability.

To determine which protein isoforms are found in the zebra finch brain, we probed juvenile zebra finch brain extracts with an antibody raised against aa 613-715 of mFoxp2 (Lu et al., 2002) by Western blot. This antibody should recognize all four isoforms. We could exclude the existence of abundant levels of the short isoforms III and IV, because no protein corresponding to their predicted molecular weight (Fig. 1A) was detected (Fig. 1E). Thus, isoforms III and IV are present only in a small population of cells or at low levels across most cells. In zebra finch brain, one or both of the long isoforms (I and II) predominate, although we could not distinguish between their similar molecular weights of 77 and $79 \mathrm{kDa}$, respectively (Fig. $1 E$ ). For the mFoxp2 protein, a molecular weight in this range has been observed (Lu et al., 2002).

The zfFoxP2 protein (isoform I) shares $98.2 \%$ identity with the human FOXP2 protein and 98.7\% identity with mouse Foxp2 protein (supplemental Fig. $1 \mathrm{~A}$; available at www.jneurosci.org). This underscores the extreme degree of conservation of the FoxP2 gene (Enard et al., 2002; Zhang et al., 2002), because $\sim 320$ million years ago is the latest time at which modern mammals and birds shared a common ancestor (Evans, 2000). At five amino acid positions that are identical in mice and men, zfFoxP2 differs. At three additional positions, the mouse and zebra finch sequence are identical but the human sequence diverges. Of these three amino acids, one also exists in carnivores (Zhang et al., 2002) (supplementary Fig. $1 A$, amino acid framed by circle), one is common to primates (supplementary Fig. $1 A$, boxed amino acid), and one is unique to humans (supplementary Fig. $1 \mathrm{~A}$, amino acid framed by triangle). In an analysis of FOXP2 molecular evolution, the latter has been suggested to result from positive selection during recent primate evolution, indicating that human FOXP2 might have been pivotal for the development of 
A
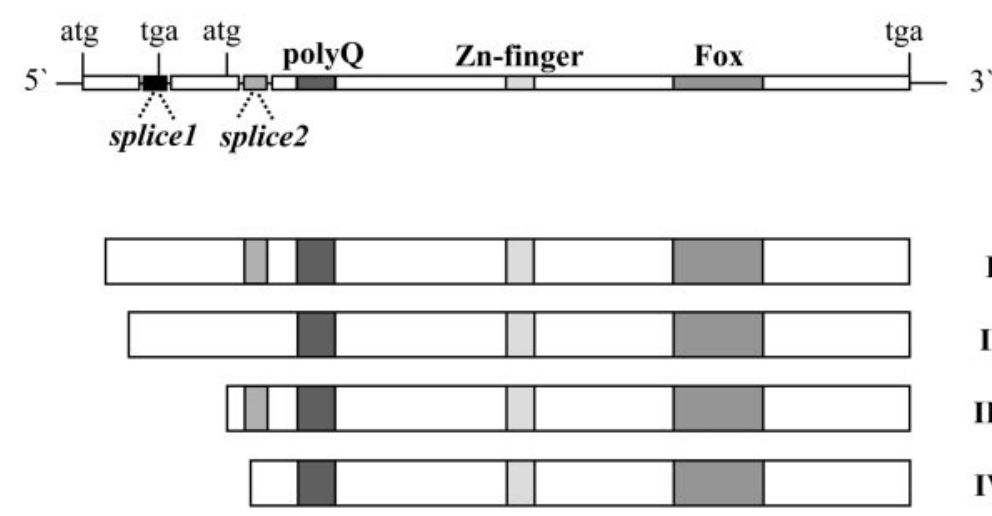

\section{,}

के हैं हैं

I $\quad+79$

II $\quad-\quad 77$

III ++69

$\mathrm{IV}+-66$

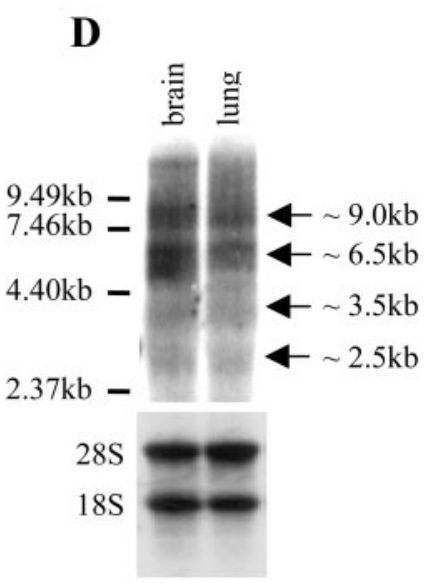

B

\begin{tabular}{ccc}
\hline isoform & $\begin{array}{c}\text { length of } \\
\text { ORF } \\
\text { (bp / AA) }\end{array}$ & $\begin{array}{c}\text { length of RT-PCR } \\
\text { product spanning } \\
\text { alternatively } \\
\text { spliced region* }\end{array}$ \\
\hline I & $2464 / 711$ & 774 \\
II & $2404 / 691$ & 714 \\
III & $1860 / 619$ & 845 \\
IV & $1800 / 599$ & 785 \\
\hline * bp 114-959 relative to first start codon
\end{tabular}

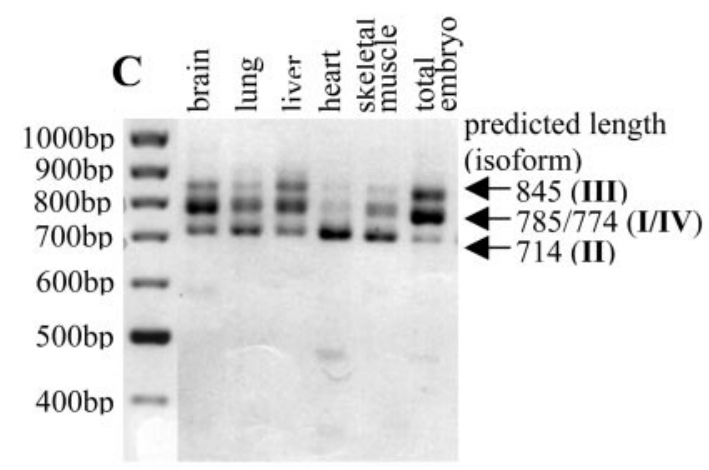

$\mathbf{E}$

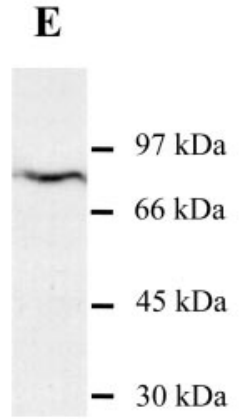

Figure 1. Identification of the zebra finch FoxP2 (zfFoxP2) mRNA. A, Schematic representation of the zfFoxP2 mRNA structure and its four predicted protein isoforms (I-IV). Positions of start (atg) and stop (tga) codons, the polyglutamine tract (polyQ), zinc finger (Zn-finger), and forkhead box (Fox) DNA-binding domains are shown. Two mRNA segments (splice1 and splice2) are subject to alternative splicing. The presence $(+)$ or absence $(-)$ of splice 1 and splice 2 leads to variation in the length of ORFs. Splice 1 contains a stop codon that shifts the frame so that the $0 R F$ begins at the second atg, splice2 inserts $60 \mathrm{bp}$ in-frame into the coding region. The four predicted protein isoforms are shown. For the calculation of their theoretical molecular weight, we used Peptide Mass (http://www.expasy.org/tools/peptide-mass.html). B, Summary of length [in base pairs (bp) and amino acid (AA)] of the zfFoxP2 isoforms (I-IV) and the length of the RT-PCR products spanning the alternatively spliced region. C, RT-PCR on RNA of different zebra finch tissues spanning the alternatively spliced region, but not the entire ORF, yields DNA fragments of the expected sizes shown in B. D, Northern blot analysis of $20 \mu \mathrm{g}$ of total RNA from adult zebra finch brain and lung was performed with a ${ }^{32}$ P-labeled DNA fragment spanning bp 114 -959 (relative to the first start codon of isoform III). Ethidium bromide staining of $18 \mathrm{~S}$ and $28 \mathrm{~S}$ ribosomal bands demonstrates equal RNA loading. The different ZfFoxP2 transcripts are indicated with arrows. E, Western blot analysis of 50 $\mu \mathrm{g}$ of brain nuclear protein extract from a 40-d-old male zebra finch reveals a zfFoxP2 protein corresponding in size to either isoform I or Il, recognized by a polyclonal antibody raised against aa 613-715 of mouse Foxp2 (Lu et al., 2002).

human language (Enard et al., 2002). ZfFoxP2 lacks this humanspecific amino acid change.

In addition, we cloned $z$ FFoxP1, the closest homolog to zfFoxP2. With 5' and 3' RACE, we assembled 2412 bp of $z f F o x P 1$ mRNA covering the ORF and 164 bp of the 3' UTR (GenBank accession number AY54952). ZfFoxP2 and zfFoxP1 amino acid sequences are highly similar (supplementary Fig. $1 B$ ), with the biggest differences being that zfFoxP1 misses the poly-glutamine stretch and 100 amino acids on the $\mathrm{N}$ terminus. For human FOXP1, an isoform that lacks the first 100 amino acids is reported (Banham et al., 1999), suggesting that we found a short zfFoxP1 isoform. The high degree of similarity between zfFoxP2 and zfFoxP1 is consistent with their reported synergistic molecular function (Li et al., 2004).

\section{Expression pattern of $z$ fFoxP2}

In all brain regions that expressed FoxP2 mRNA (ISH), the Foxp2-specific antibody (IHC) also strongly labeled nuclei, as is expected for a transcription factor.

Consistent with the reports from developing human and mouse brain (Shu et al., 2001; Lai et al., 2003; Takahashi et al., 2003), we detected FoxP2 expression in the embryonic zebra finch brain as early as stage 26 (Hamburger and Hamilton, 1951;
Butler and Juurlink, 1987) (Fig. 2A). The highest expression was in the striatum and dorsal thalamus. This expression persisted throughout development (Fig. 2B) and was not restricted to vocal learners, because chickens also showed strong expression in the embryonic striatum (Fig. 2C). Closer examination at stage 34 revealed that the basal plate of the telencephalic vesicle, part of which gives rise to dorsal striatal areas in the adult, expressed FoxP2 (Fig. 2D), as did the region that develops into the dorsal thalamus (data not shown). In the ventral midline of the mesencephalic vesicle, labeled cells appear to invade the laterally adjacent neuroepithelium (Fig. 2E). At limb levels of the spinal cord, cells that appear to be departing the roof plate and migrating to ventromedial regions expressed FoxP2 (Fig. $2 F$ ). Expression was strong in the floor plate at this level, extending rostrally into the mesencephalon (Fig. 2F). The lateral margins of the hindbrain neuroepithelium and the region of the metencephalic/mesencephalic isthmus also strongly expressed FoxP2.

Throughout zebra finch post-hatch development and into adulthood the striatum and nuclei in posterior portions of the dorsal thalamus dominated expression (Fig. $3 A-F$ ). Expression levels in the striatum decreased slightly with age (Fig. $3 H$ ). Expression levels in pallial regions (i.e., those dorsal to the striatum) remained low throughout development and into adulthood (Fig. 
$3 H)$. The prominent expression in the striatum and the dorsal thalamus was common to all birds, because this pattern was present in all species investigated and in both genders, regardless of whether they are vocal learners (Fig. $4 A-G$ ) or not (Fig. $4 H$ ), and even in a crocodile (Fig. $4 I$ ), the closest non-avian relative.

\section{ZfFoxP2 expression in a striatal song} nucleus during stages of vocal plasticity In vocal learners, the dorsal striatum contains a nucleus that is part of the specialized song system, called Area X in songbirds, vocal nucleus of the anterior striatum [VAS; previously called VAP (Jarvis et al., 2000)] in hummingbirds, and magnocellular nucleus of the medial striatum [MMSt; previously called LPOm (Striedter, 1994)] in parrots. This structure is part of a basal ganglia loop, the so-called anterior forebrain pathway (AFP) (Bottjer and Johnson, 1997; Durand et al., 1997; Farries and Perkel, 2002) and is essential for vocal learning (Sohrabji et al., 1990; Scharff and Nottebohm, 1991). During development, Area $\mathrm{X}$ in male zebra finches expressed more FoxP2 mRNA than the surrounding striatum only at PHDs 35 and 50, the age at which zebra finches actively learn how to imitate song (Fig. 3C,D) (Tchernichovski et al., 2001). Before this period (at PHDs 15 and 25) and afterward, when birds crystallized their songs (PHD 75) and became adults (more than PHD 120), FoxP2 expression in Area $\mathrm{X}$ did not differ from expression in the surrounding striatum. In adults, there was variability. Of 10 adult male zebra finches examined, 7 had expression levels in Area X similar to the region surrounding it, two slightly lower and one slightly higher. We could not find a variable (song complexity, amount of singing, or age at sacrifice) that could account for this adult variability. Female zebra finches, which do not learn song and do not have an Area X song nucleus, did not show any differential FoxP2 expression in the region where Area $\mathrm{X}$ is located in males.

We also examined FoxP2 expression in adult male canaries during different seasons of the year using a collection of canary brain sections described by Jarvis and Nottebohm (1997) (also see Materials and Methods). In July, August, and September, canaries expressed more FoxP2 mRNA in Area X than in the region surrounding it (Fig. 5). These are the months when birds add new syllables into their song repertoire and song is more variable (Nottebohm et al., 1986; Leitner et al., 2001) than in the preceding breading season, when song is stable. Breeding occurs in spring and can last through the end of June, and FoxP2 expression during this time (sampled in April and May) did not differ from the surrounding region. This was also the case in October and January (Fig. 5).

To rule out that the developmental and seasonal changes in Area X FoxP2 expression were the result of a generic feature of gene expression in this region, we compared the zebra finch glutamate receptor subunits NR2B and $m G l u R 2$ (Wada et al., 2004) on adjacent sections to those that were probed with FoxP2. We found no differences in $m G l u R 2$. There were some developmental changes in NR2B expression in zebra finch Area X at PHD 25,
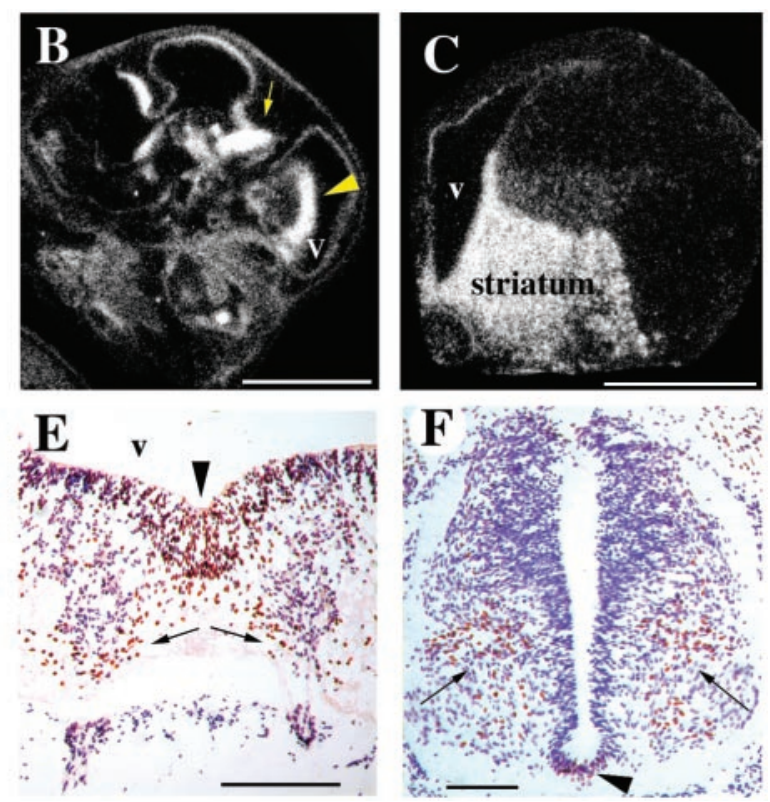

Figure 2. Embryonic FoxP2 mRNA ( $A-C)$ and protein ( $D-F)$ expression. Sagittal sections through stage $26(A)$ and $34(B)$ zebra (arrowheads) and presumptive dorsal thalamus (arrow). The heads face

as expected from a previous report (Basham et al., 1999). However, the ratio of $N R 2 B$ expression levels between Area $\mathrm{X}$ and the surrounding striatum remained similar at PHDs 35-75 (supplementary Fig. 2), the time when the FoxP2 expression ratio was higher. In canaries, we observed no seasonal changes of $N R 2 B$ expression in Area X, as was also shown previously (Singh et al., 2003).

We further tested whether some of the observed variability of FoxP2 expression in Area X could be accounted for by singing activity. Singing strongly induces the expression of the immediate early gene ZENK (the avian homolog of mammalian zif268/EGR-1/ NGFI-A/krox24 gene) in Area X (Jarvis and Nottebohm, 1997). Moreover, the $5^{\prime}$ flanking region of human FOXP2 contains three predicted EGR-1 (i.e., ZENK) binding sites (Bruce and Margolis, 2002). We found that for birds of similar age or season there were no significant differences in FoxP2 mRNA expression between quiet control animals (quiet for at least $12 \mathrm{hr}$ overnight) and animals that sang spontaneously [for 30 or $60 \mathrm{~min}$ for zebra finches ( $n=3$ each) and 1, 15, 30, or 60 min or 2, 4, or $6 \mathrm{hr}$ for canaries $(n=3$ each) , whereas $Z E N K$ was induced dramatically in zebra finches at PHD 65 or 150 by singing during the last 30 min before sacrifice (Jarvis and Nottebohm, 1997) (supplementary Fig. 3)

FoxP2 expression in Area $\mathrm{X}$ of adults of four other songbird species and in the corresponding region VAS in hummingbirds also differed relative to the surrounding striatum (Fig. 4). In chickadees and strawberry finches, both seasonal breeders (Langham, 1987; Smith, 1991), FoxP2 expression was higher in Area X than in the surrounding striatum (Fig. $4 A, B, J$ ). In song sparrows and Bengalese finches, FoxP2 expression was lower than the sur- 

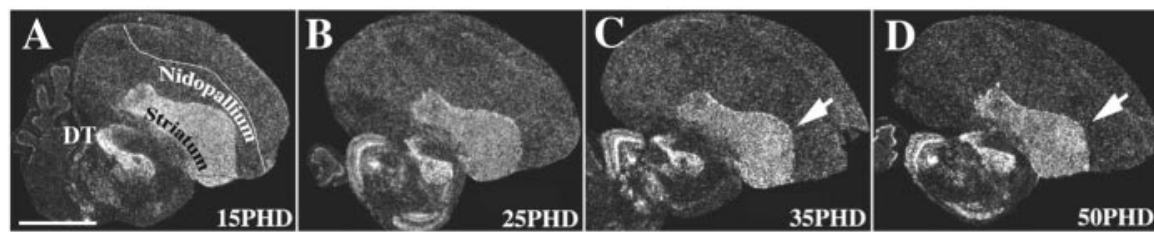

G

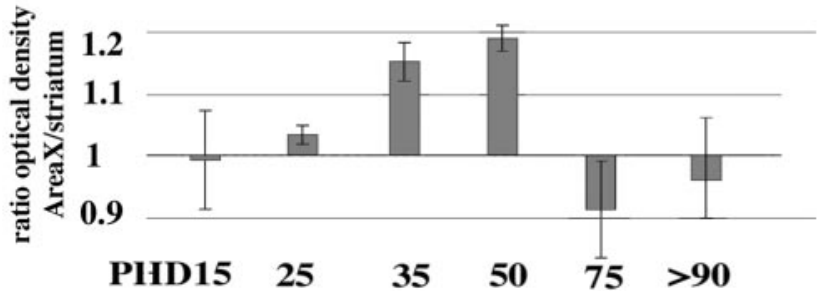

$\mathbf{H}$

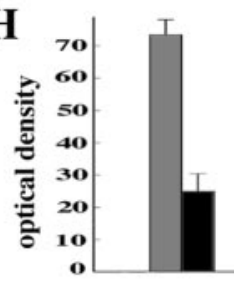

PHD15 25
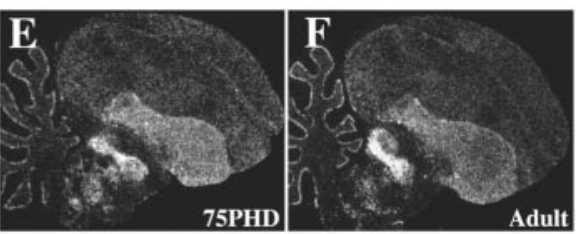

Nidopallium (dorsal and caudal to Area X) - Striatum (ventral to Area X)
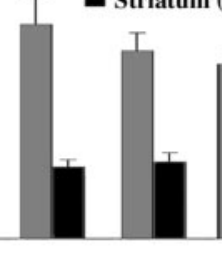

35

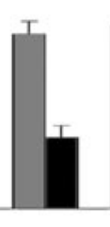

50

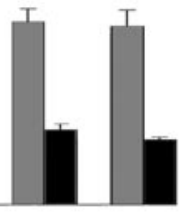

$75>90$

Figure 3. Differential FoxP2 expression in Area $X$ during post-hatch zebra finch development ( $A-F$ ). Area $X$ expressed more zfFoxP2 than the surrounding striatum only at PHDs 35 and 50 ( $C, D$, arrowheads), which is the time when zebra finches learn to imitate song. $G$ and $H$ show the results of autoradiographic densitometric quantification of expression levels at the different ages ( $n=$ 3 for each age). The ratio of expression between Area $X$ and the surrounding striatum increased during the phase when song imitation occurs on PHDs 35 and 50 ( $G$ ). Absolute levels of FoxP2 expression in the nidopallium did not change throughout development, whereas in the striatum (outside of Area X) they decreased slightly from PHDs 15 to 25 and reached adult levels by PHD 35 (H). Scale bar (in $A$ ): $A-F, 2 \mathrm{~mm}$.
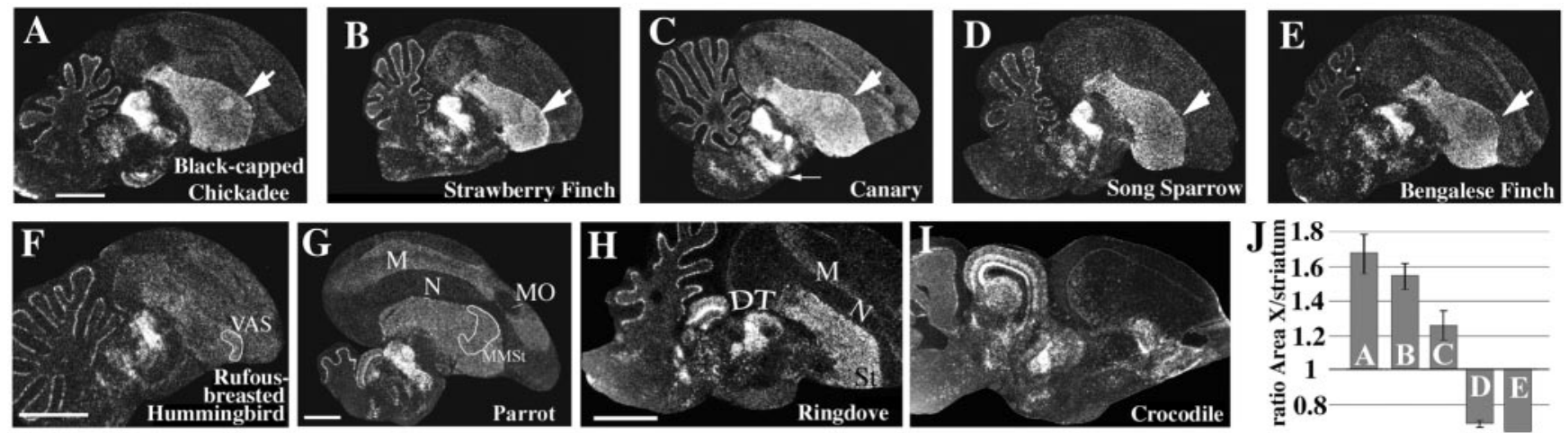

Figure 4. Different adult vocal learners $(A-G)$, non-learners $(H)$, and a crocodile $(I)$ shared the FoxP2 expression pattern in the striatum and dorsal thalamus (DT) but differed in expression levels in the striatal vocal nucleus (Area X/VAS/MMSt). Area X of chickadees (sampled in the fall), strawberry finches (sampled on long day photoperiod), and canaries (sampled in July) expressed more FoxP2 in Area $X$ than in the surrounding striatum ( $A-C$, reflected in higher expression ratios (bars $A-C$ in $)$ ). Area $X$ of song sparrows (sampled in spring) expressed slightly less FoxP2 than the surrounding striatum ( $D$; bar $D$ in $J$ ), as did Bengalese finch ( $E$; bar $E$ in $J$ ). The rufous-breasted hermit hummingbird ( $F$ ) had slightly higher expression in the VAS, and the parrot ( $G$ ) did not show a difference between vocal nucleus MMSt and the surrounding striatum. The adult ringdove $(H)$, a bird that does not exhibit vocal learning and lacks telencephalic vocal nuclei, expressed high levels of FoxP2 mRNA in the striatum and DT, as did a crocodile ( $/$ ). The arrow in ( points to the high levels of FoxP2 expression in the substantia nigra pars compacta. M, Mesopallium; M0, oval nucleus of the mesopallium; $\mathrm{N}$, nidopallium; St, striatum; VAS, vocal nucleus of the anterior striatum; MMSt, magnocellular nucleus of the medial striatum. Scale bars (in $A$ for $A-E$; in $H$ for $H, I$ ), 2 mm.
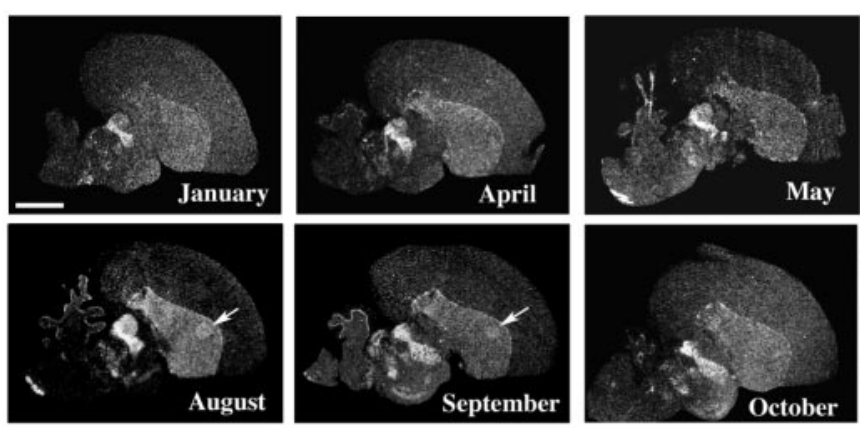

Figure 5. FoxP2 expression in Area X of adult canaries varied seasonally. Area X expressed noticeably more FoxP2 than the surrounding striatum only during the months of July, August, and September, resulting in higher ratios of Area X to striatum expression (the bar graph shows the mean ratios for each month, and superimposed points represent the values for individual birds).

rounding striatum (Fig. $4 D, E, J$ ). The chickadees were caught during the fall months (October and November), whereas the song sparrows were caught during late spring (April and May) (Jarvis et al., 1997), when song sparrows sing fewer variations of
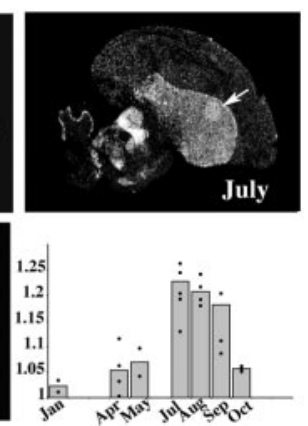

song types and song is more stereotyped than in the fall (Smith et al., 1997). Bengalese finches are not strongly seasonal birds and breed opportunistically (Seiler et al., 1992), as do zebra finches, although the latter are also sensitive to photoperiod (Bentley et al., 2000). Rufous-breasted hummingbirds, captured near the end of their breeding season (Jarvis et al., 2000), showed slightly elevated levels of FoxP2 in the hummingbird striatal vocal nucleus VAS (Fig. $4 F$ ). We did not find differential expression in MMSt of parrots (Fig. 4G). To address the source of the differences in FoxP2 expression in Area X/VAS/MMSt among different species, we checked whether they might be related to differences in overall vocal syntax complexity, using the equations of Scharff and Nottebohm (1991). Scores of vocal syntax complexity are low when song elements are mostly rendered in an unvarying, 
stereotyped manner. When songs consist of elements that are rendered in highly variable sequences, scores of syntax complexity are high. Vocal syntax complexity is low in strawberry finch, zebra finch, and somber hummingbird; intermediate in Bengalese finch, canary, and song sparrow; and high in rufous-breasted hermit hummingbird and budgerigar (K. Wada and E. D. Jarvis, unpublished observation). Thus, vocal syntax complexity cannot account for the observed FoxP2 expression differences among the species (data not shown). Instead, the FoxP2 expression pattern in chickadee, strawberry finch, and song sparrow are more consistent with the notion that during times of increased song stereotypy, as is usually observed during the breeding season, FoxP2 is not upregulated in Area X, whereas outside of the breeding season, when song tends to be more plastic, FoxP2 expression in Area $\mathrm{X}$ tends to be higher.

Hummingbirds and parrot differed with respect to pallial expression from the six songbird species investigated. In the hummingbird, the differential higher expression of FoxP2 in the striatum relative to the pallium was less pronounced than in the other species. In the parrot, FoxP2 expression in mesopallium was much higher relative to other pallial regions than it was in the other species tested. However, the AFP mesopallial song nucleus [MO; previously called HVo (Jarvis and Mello, 2000)] had low FoxP2 expression (Fig. 4G). None of the other pallial vocal nuclei of the parrot, songbird, or hummingbird AFP (songbird IMAN like) or vocal nuclei of their motor pathways (songbird HVC like, used as a proper name, and RA like) expressed high levels of FoxP2.

\section{Cellular identity of zfFoxP2-expressing cells}

In adult zebra finch striatum, Foxp2 immunoreactivity was characteristically seen in medium or small cells that were uniformly distributed throughout, except for one peculiarity. Small Foxp2positive cells formed distinct, evenly spaced clusters in the part of the lateral striatum that abuts the pallial-subpallial lamina (PSL; previously called LMD), which separates the pallium from subpallium (Fig. $6 A, B$ ). More medially in the striatum these clusters formed a thin, continuous band (data not shown), matching the high levels of mRNA seen at the striatum side of the PSL (Fig. $3 F$ ). In pigeon striatum, similarly arranged patches contain dense ChAT-immunoreactive fibers (Medina and Reiner, 1994). In zebra finch, these Foxp2-immunoreactive cell clusters were, likewise, innervated by ChAT (Fig. 6C). The clusters were also visible in Nissl-stained material (Fig. 6D). A Hu antibody, which binds to an RNA-binding protein specifically present in young postmitotic and adult neurons (Barami et al., 1995), revealed that all Foxp2-immunoreactive brain cells were neurons, including the clusters at the PSL in the striatum (Fig. 6E,F). Some of the latter also expressed PSA-NCAM, a marker for cellular plasticity and migration (Durbec and Cremer, 2001) (Fig. 6G).

To determine whether the FoxP2-expressing neurons in the striatum belonged to a particular population of neurons, we used markers for the three classes of striatal interneurons (Reiner et al., 1998, 2004a) in conjunction with Foxp2 IHC:ChAT to detect the large, aspiny cholinergic interneurons, nitric oxide synthase (nNOS) to detect the medium-sized aspiny interneurons that also contain somatostatin and NPY, and the calcium binding protein parvalbumin to detect another population of mediumsized aspiny interneurons that also contain GABA and the neurotensin-related hexapeptide LANT6 (Reiner et al., 1998, 2004a). Neither ChAT (Fig. 6J) nor nNOS (Fig. 6K) nor parvalbumin (Fig. 6L) were detected in the same neurons as FoxP2, suggesting that the striatal neurons that express FoxP2 are pro-
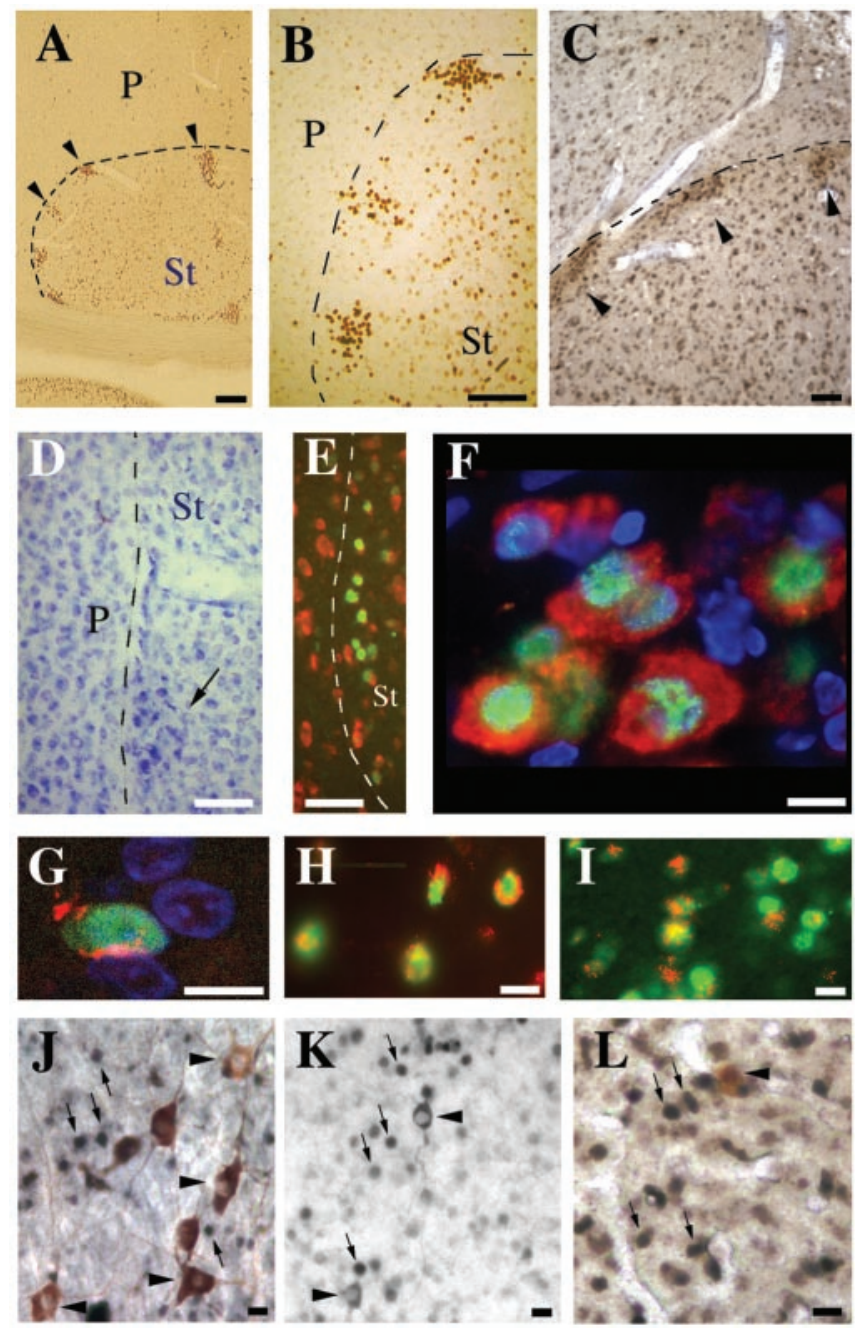

Figure 6. FoxP2 expression in distinct populations of neurons in adult zebra finches. Low $(A)$ and high $(B)$ magnification of a sagittal section showing the dorsolateral extent of the subpallial-pallial (P) border with the striatum (St; black dashed line), where clusters of cells in the dorsal and lateral striatum express FoxP2 (arrowheads; brown immunoreactivity). Dorsal is up, and rostral is to the right. C, These clusters (arrowheads; black-brown immunoreactivity) are characterized by dense ChAT fiber staining (lighter brown immunoreactivity). D, Clusters visualized with cresyl violet stain. E, FoxP2-immunoreactive cells within the clusters are neurons as shown by double labeling with fluorescent anti-Hu (red) and anti-FoxP2 (green). F, Higher magnification in the dorsal thalamus shows that the cytoplasmic neuronal anti-Hu antibody (red) colocalizes with nuclear FoxP2 antibody staining (green). FoxP2-negative nuclei can been seen in blue, stained with nuclear 4' 6-diamidino-2-phenylindole DNA stain. G, Some FoxP2positive cells are recognized by anti-PSA-NCAM antibody, a cell adhesion protein (PSA-NCAM, red; FoxP2, green; TOPRO3 nuclei, blue). $H$, Striatal neurons also coexpress DARPP-32 (red) and FoxP2 (green) and appear to be innervated by TH-positive (red) terminals ( $/$ ). Colabeling with neurochemical markers for three different striatal interneuron populations $[\operatorname{ChAT}(J), \mathrm{nNOS}(K)$, or parvalbumin ( $L$ ) (brown cytoplasmatic labeling; arrowheads)] revealed that FoxP2 (black nuclear labeling; arrows) was not expressed in these cell types. Scale bars: $A, B, 100 \mu \mathrm{m} ; C-E, 50$ $\mu \mathrm{m} ; F-L, 10 \mu \mathrm{m}$.

jection neurons rather than interneurons. It is known that the striatal neurons that project to the pallidum in birds, as in mammals, and striatal neurons that project to pallidal-like cells in Area $\mathrm{X}$ are the site of convergent nigral dopaminergic and cortical (i.e., pallial) glutamatergic input (Reiner et al., 1998, 2004a). DARPP-32 is thought to serve as a critical integrator of these two inputs onto the striatal projection neurons (Hemmings et al., 1995). Concordant with our expectation that FoxP2 is expressed in striatal projection neurons, we found two indicators of dopa- 
Table 1. Expression patterns of FoxP2 in subtelencephalic brain regions of adult zebra finch

\begin{tabular}{|c|c|c|}
\hline Abbreviation & Subtelencephalic region & FoxP2 \\
\hline AN & Nucleus angularis & + \\
\hline DM & Dorsomedial nucleus of the midbrain & - \\
\hline DT & Dorsal thalamus (posterior nuclei) & +++ \\
\hline nlll & Cranial nucleus III (Edinger-Westphal) & - \\
\hline $\mathrm{Cn}$ & Cuneate nucleus & + \\
\hline Gn & Gracile nucleus & + \\
\hline $\mathrm{GCt}$ & Substantia grisea centralis & + \\
\hline Imc & Nucleus isthmi, pars magnocellularis & - \\
\hline Ipc & Nucleus isthmi, pars parvocellularis & - \\
\hline 10 & Nucleus isthmo-opticus & + \\
\hline La & Nucleus lateralis anterior thalami & + \\
\hline LLi & Nucleus lemnisci lateralis & + \\
\hline MC & Nucleus magnocellularis & + \\
\hline MLd & Nucleus mesencephalicus lateralis, pars dorsalis & ++ \\
\hline $\mathrm{MnV}$ & Motor part of trigeminal nucleus or V nucleus & - \\
\hline $\mathrm{MnX}$ & Dorsal motor part of the vagus nucleus or $\mathrm{X}$ nucleus & - \\
\hline $\mathrm{nBOR}$ & Nucleus of the basal optic root & - \\
\hline $\mathrm{nIX}$ & Glossopharyngial nucleus or IX nucleus & - \\
\hline$n V I$ & Abducens nucleus or VI nucleus & - \\
\hline nXII & Hypoglossal nucleus or XII nucleus & - \\
\hline Ol & Nucleus olivaris inferior & +++ \\
\hline Omd & Nucleus nervi oculomotorii, pars dorsalis & - \\
\hline OMdm, $0 \mathrm{Mv}$ & Nucleus nervi oculomotorii, pars dorsalis/ventralis & - \\
\hline $\mathrm{OMv}$ & Nucleus nervi oculomotorii, pars ventralis & \\
\hline $0 v$ & Nucleus ovoidalis & + \\
\hline PAG & Periaqueductal gray & + \\
\hline PMH & Nucleus medialis hypothalami posterior & + \\
\hline PT & Pretectal nucleus & - \\
\hline PTD & Nucleus pretectalis diffusus & - \\
\hline PTM & Nucleus pretectalis medialis & ++ \\
\hline PVN & Paraventricular nucleus & - \\
\hline Rt & Nucleus rotundus & ++ \\
\hline $\mathrm{RPC}$ & Nucleus reticularis pontis caudalis & + \\
\hline $\mathrm{R}$ & Red nucleus & + \\
\hline ST & Nucleus of the solitary tract & + \\
\hline SNC & Substantia nigra, pars & + \\
\hline SP & Nucleus subpretectalis & - \\
\hline SpL & Nucleus spiriformis lateralis & - \\
\hline $\mathrm{T}$ & Nucleus triangularis & ++ \\
\hline VeD & Nucleus vestibularis descendens & + \\
\hline VeL & Nucleus vestibularis lateralis & + \\
\hline VTA & Ventral tegmental area & + \\
\hline
\end{tabular}

minergic innervation. Foxp2-immunoreactive striatal neurons coexpressed DARPP-32 (Fig. $6 H$ ), which is indicative of the presence of dopamine D1 receptors (Snyder et al., 1998), and immunoreactivity for $\mathrm{TH}$, the synthetic enzyme for biogenic amines, was present in fibers around perikarya of neurons with Foxp2immunoreactive nuclei (Fig. 6I).

\section{ZfFoxP2 expression in subtelencephalic brain regions}

Table 1 lists subtelencephalic structures that did or did not express FoxP2. For identification of subtelencephalic brain regions, we analyzed serial frontal and sagittal sections through the entire brain of male zebra finches and used the region-specific parvalbumin (Braun et al., 1985, 1991; Wild et al., 2001) and ChAT (Medina and Reiner, 1994) staining in adjacent series of sections as landmarks to ascertain the identity of brain regions that expressed FoxP2 (Fig. 7 B, C, H, I). FoxP2 expression was prominent in dopaminergic midbrain regions that project to the basal ganglia, the substantia nigra/ventral tegmental area (Fig. 4C, small white arrow), and in caudal regions of the dorsal thalamus (Figs. $3 A-F, 4 A-I, 5)$. In addition, FoxP2 was expressed in many regions that are involved in relaying and integrating ascending sensory information, including auditory regions [e.g., midbrain nucleus MLd (dorsal part of the lateral mesencephalic nucleus) (Fig. $7 A, B)$ and thalamic nucleus ovoidalis (data not shown)], visual regions [e.g., afferent upper layers of midbrain optic tectum (Fig. $7 A, F)$ and thalamic nucleus rotundus (Fig. 7D)], multimodal regions [e.g., layers 10 and 11 of the optic tectum (Fig. $7 F$ )], and somatosensory regions [e.g., sensory trigeminal (data not shown)]. Prominent FoxP2 expression was observed in the Purkinje cells of the cerebellum (Figs. $3 E, F, 4 A-I, 7 E$ ) and the inferior olive (Fig. $7 G$ ), which gives rise to all the climbing fibers innervating the Purkinje cells. All species tested, including males and females, regardless of whether they learn their vocalization or not, expressed FoxP2 in these regions. In contrast, FoxP2 expression was not found in midbrain and brainstem motor control areas, such as the vocal nucleus DM (dorsomedial motor nucleus of the intercollicular region) (Fig. $7 B, C$ ), the hypoglossal vocal and tongue nucleus, nXII (Fig. $7 \mathrm{H}, \mathrm{I}$ ), and most other motor cranial motor nuclei (Table 1).

\section{ZfFoxP1 expression}

Similar to FoxP2, FoxP1 was expressed at high levels in the striatum and in the dorsal thalamus of zebra finches and other birds (Fig. 8A-F). Unlike FoxP2, FoxP1 expression in the striatal vocal nuclei (Area X or MMSt) was similar across development and season, across all songbirds tested, and in parrots (i.e., higher expression in the striatal vocal nucleus relative to the immediate surrounding striatum) (Fig. $8 A-D, F$ ). Also unlike FoxP2, within the pallium, FoxP1 was consistently and prominently expressed in the mesopallium in all avian species tested (Fig. $8 A-F$ ). Interestingly, for the three main songbird pallial vocal nuclei (IMAN, HVC, and RA), FoxP1 expression differed notably from the expression of the subdivisions in which these nuclei are embedded. HVC and RA strongly expressed FoxP1, whereas the surrounding territories did not. The reverse was true for $1 \mathrm{MAN}$, which did not express FoxP1, while the region around it did (Fig. $8 A-D$ ). This was consistent across songbird species. The parrot pallial analog of HVC, the central nucleus of the nidopallium, had noticeably higher levels than the surrounding nidopallium (Fig. $8 F$ ). In contrast to FoxP2, FoxP1 was never expressed in the Purkinje cells of the cerebellum. FoxP1 expression in the ring dove brain was similar to that of the songbirds and parrot, with the exception that there was no differential expression in the striatum and pallium, where vocal nuclei are found in vocal learners (Fig. $8 E$ ). A telencephalic expression pattern remarkably similar to that of the avian brain was found in crocodile (Fig. $8 G$ ), including high expression in striatal-like and mesopallium-like regions. This suggests that the general FoxP1 and FoxP2 expression patterns in vocally learning and non-learning birds were inherited from their common reptilian ancestor.

\section{Discussion}

We set out to answer three questions: (1) Is FoxP2 differentially expressed in the brains of avian vocal learners and non-learners? (2) How does FoxP2 expression in birds compare with FoxP2 expression in mammals? and (3) Does zebra finch FoxP2 bear molecular similarities to human FOXP2?

The answer to the first question is partly yes, partly no. Partly yes, because FoxP2 is differentially expressed in vocal nucleus Area $\mathrm{X}$, a part of the special basal ganglia forebrain network required for vocal learning that vocal non-learners do not possess. 
Moreover, FoxP2 expression is elevated in Area $\mathrm{X}$ at the time when young zebra finches learn to imitate song and during the time when adult canaries remodel their songs. In addition, in adults of six different species, Area X (and in the equivalent structure VAS in the hummingbird) showed consistent differences in FoxP2 expression, being either higher or lower than the surrounding striatum, in a pattern consistent with periods of change in vocal behavior. Lesions of Area $\mathrm{X}$ in zebra finches during vocal learning result in adult song production that is more plastic than when Area X is intact (Sohrabji et al., 1990; Scharff and Nottebohm, 1991), suggesting that Area X helps generate song stability. If FoxP2 acts as a transcriptional repressor in the brain, as it does in the lung (Shu et al., 2001; Lu et al., 2002; Li et al., 2004), then the higher levels found during periods of vocal plasticity might suggest that FoxP2 represses genes that are involved in neural stability in Area X. These findings and interpretation are compatible with a role for FoxP2 in learned vocalization.

The answer to question (1) is partly no, because FoxP2 was expressed in non-vocal striatal regions outside of Area X/VAS/ MMSt of all 11 bird species examined and was similar regardless of whether or not they learn their vocalizations. Both vocal learners and vocal non-learners had similar developmental onset of FoxP2 expression in comparable brain regions and equivalent expression patterns in adults. The strongest signal was consistently observed in the striatum of the basal ganglia, nuclei of the dorsal thalamus and midbrain, the inferior olive, and the Purkinje cells of the cerebellum. Less intense, but consistent, expression was observed in various nuclei connected to these regions.

Our second question concerned the comparison of our data with those found in mammals. Recent publications of FOXP2 expression in the human, rat, and mouse brain (Ferland et al., 2003; Lai et al., 2003; Takahashi et al., 2003) report essentially concordant striatal and subtelencephalic sites of FoxP2 expression with those we and another group (Teramitsu et al., 2004) found in birds. We also noted a similar striatal expression pattern in a closely related reptilian species to birds, the crocodile. Birds expressed little FoxP2 in pallial regions, with the exception of the mesopallium, and this varied between species. Mammals also expressed little FoxP2 in pallial regions, with the exception of cortical layer 6 (Ferland et al., 2003). The expression of FOXP1 in mammals (Ferland et al., 2003) is also concordant with the expression we and Teramitsu et al. (2004) found in birds for striatal and subtelencephalic sites. In pallial regions, relative to FoxP2, birds expressed more widespread FoxP1, with the highest expression occurring in the mesopallium and in vocal nuclei HVC
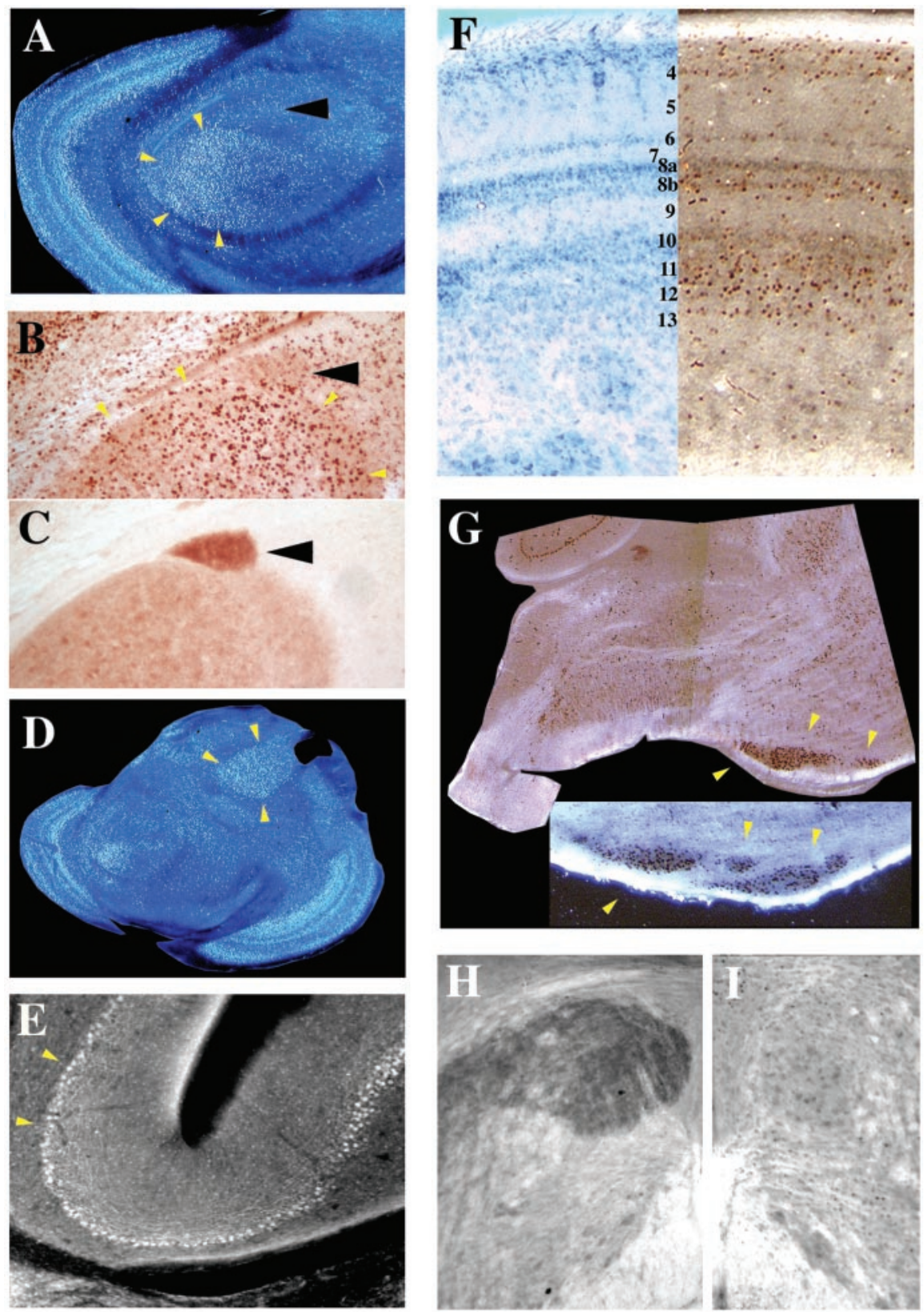

Figure 7. FoxP2 expression in subtelencephalic regions was associated more with afferent sensory or multimodal areas rather than with pure motor areas. Auditory nucleus MLd (dorsal part of the lateral mesencephalic nucleus) expressed FoxP2 (white dark-field label in $A$ and brown label in $B$; both surrounded by yellow arrowheads). In contrast, the dorsomedial motor nucleus of the intercollicular region (DM), which controls vocalizations, showed little mRNA and immunoreactivity for FoxP2 ( $A, B$, black arrowheads) but strong parvalbumin immunoreactivity (C) (Braun et al., 1985). Also, FoxP2-immunoreactive cells were seen in the visual thalamic nucleus rotundus $(D)$, cerebellar Purkinje cells $(E)$, specific layers of the optic tectum in the midbrain $(F)$, and brainstem nucleus inferior olive $(G)$ but not in the tracheosyringeal portion of the nucleus of the hypoglossal nerve nXIItx $(I)$. We took advantage of the strong parvalbumin immunoreactivity of $n X I I$ to unambiguously identify this nucleus (adjacent section to $I$ stained with parvalbumin in $H$ ) (Wild et al., 2001). Immunoreactivity in dark-field images appears white, and in bright-field photomicrographs brown. $A, D$, and $E-G$ are sagittal sections, rostral is to the right, and $B, C, H$, and / are frontal sections. Dorsal is up in both orientations.

and RA of songbirds, but notably low levels in the tissue surrounding HVC and RA. Mammals also expressed more widespread FoxP1 levels in the pallium, cortical layers 3-5 during development, and also in layer 6 during adulthood (Ferland et al., 2003). These differences in cortical/pallial FoxP2 expression between mammals and birds are difficult to interpret because direct homologies between most avian and mammalian pallial areas remain unresolved (Reiner 

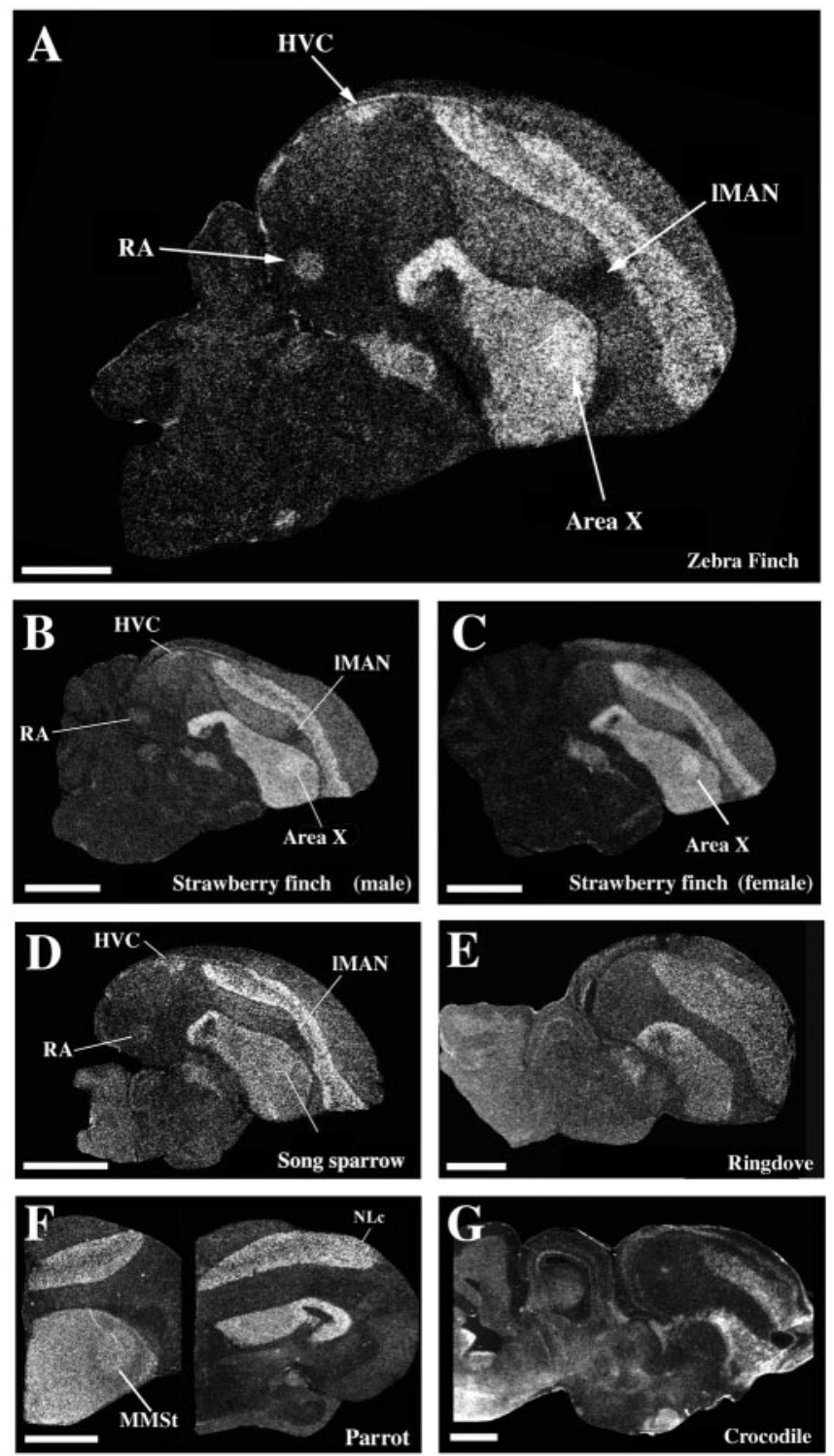

Figure 8. Expression pattern of FoxP1 was distinct from but partially overlapping with that of FoxP2. A, FoxP1, like FoxP2, was expressed in the dorsal thalamus and striatum in adult zebra finches $(A)$. In addition, it was expressed in vocal nuclei HVC, RA, and Area X (but not IMAN) at higher levels than their surrounding regions and in the mesopallium. Both male $(B)$ and female $(C)$ strawberry finches, male song sparrow $(D)$, as well as the parrot ( $F$ ) expressed more FoxP1 mRNA in Area X (MMSt in parrot) than in the surrounding striatum. $E$, A vocal non-learner, the ring dove, also expressed FoxP1 mRNA in the subpalllial and pallial areas. G, The crocodile had a telencephalic pattern very similar to that of birds. All sections are sagittal, except the parrot sections in $F$, which are frontal. Scale bars: $A-D, 1 \mathrm{~mm} ; E-G, 2 \mathrm{~mm}$.

et al., 2004b). The pallium of the avian telencephalon possesses a nuclear organization, whereas that in mammals shows a layered organization. There has been no predicted relationship between the avian mesopallium and cortical layer 6 that we are aware of (http:// avianbrain.org). The main projection of the mesopallial vocal nuclei and other mesopallial areas (previously called hyperstriatum ventrale) are to arcopallial, nidopallial, and striatal areas (Durand et al., 1997; Csillag 1999; Brauth et al., 2001), whereas those of layer 6 in mammals are to the dorsal thalamus in addition to other cortical (pallial) layers (Ferland et al., 2003). Thus, our results suggest that high striatal and subtelenphalic FoxP1 and FoxP2 expression and restricted pallial expression in birds and mammals was inherited from a common stem-amniote ancestor (Evans, 2000), but that their specific pallial patterns have either diverged or evolved independently.

We also answered question (3), whether FoxP2 might be molecularly more similar to human FOXP2 than to rodent Foxp2. We were motivated to ask this rather unlikely question because of recent reports (Enard et al., 2002; Zhang et al., 2002) that FOXP2 has been the target of positive selection during recent primate evolution, resulting in a human-specific amino acid change that is thought to be related to language (i.e., human vocal learning). If this change was pivotal to the evolution of learned vocal communication in hominids, perhaps similar selection pressure acted on the supposedly independent evolution of vocal learning in birds. Although zfFoxP2 clearly lacks the human-specific amino acid change, we cannot exclude this possibility. The fact that zebra finches, in contrast to mouse, have a $6.5 \mathrm{~kb}$ zfFoxP2 transcript that corresponds in size to the human transcript raises the possibility that selection acted on the regulatory sequences.

Taken together, we conclude that the striking conservation of the FoxP2 gene sequence and overall brain expression pattern in avian, reptilian, and mammalian brains, regardless of whether they learn to vocalize or not, confirms that FoxP2 has a more general role than to enable vocal learning. FoxP2 could be an ancient transcription factor involved in shaping cerebral architecture, perhaps via restriction of certain neuronal lineages, as reported recently for Foxg1 (Hanashima et al., 2004). If FoxP2 were involved in the development and maintenance and function of subtelencephalic and striatal sensory and sensory-motor circuits, this could create a permissive environment on which vocal learning can evolve if other factors come into play. Given the prominent role of many other forkhead transcription factors in early development, this is a likely scenario (Carlsson and Mahlapuu, 2002). Support of this notion also stems from the fact that regions of early FoxP2 expression in the avian embryo are sources of inductive signals that organize adjacent neuroepithelium and neuronal migration during early development.

The common expression pattern of FoxP2 in birds and mammals might provide valuable clues about what constitutes a "permissive environment" for vocal communication and evolution of vocal learning. Learning to imitate acoustic signals requires integration of sensory information with the desired motor output. The basal ganglia as well as the cerebellum in all vertebrates integrate afferent sensory information with descending motor commands and thus participate in the precise control of temporally sequenced muscle movements (Doyon et al., 2003). Both innate and learned avian and human vocalizations depend on such control (Doupe and Kuhl, 1999). Anatomical evidence suggests that the specialized regions for vocal learning in birds were elaborated from already modularly connected forebrain regions translating ascending auditory, somatosensory, and visual information into motor commands. Consistent with this, an AFP-like circuit apparently also exists in vocal non-learners (Farries, 2001). In humans, the basal ganglia and the cerebellum have attracted far less attention than the cortical speech and language areas, but there is increasing awareness that the basal ganglia and cerebellum are not only essential for the execution but might also be required for the acquisition of human vocal behavior (Lieberman, 2001; Marien et al., 2001).

Besides having the advantage of being able to study anatomical structures involved with learned vocal communication, our study also differs from the rodent and human studies in that we specifically investigated the distribution of FoxP2 in cranial motor nuclei. It has been suggested that the speech and language pathology in humans with FOXP2 mutations consists of an oro- 
facial dyspraxia core deficit (for review, see Marcus and Fisher, 2003). This could be primarily attributable to a lack of muscle control over the speech apparatus. However, our data suggest that in birds FoxP2 is, for the most part, expressed in afferent sensory pathways and in the striatal projection neurons, which are the site of convergence for both pallial and subpallial projections. Takahashi et al. (2003) also argue that in rats FoxP2positive striatal neurons are projection neurons, based on selective FoxP2 expression in the lateral ganglionic eminence but not the medial ganglionic eminence and the known precursor populations of these germinal regions (Parnavelas et al., 2002). In addition, many sites of FoxP2 expression, such as the inferior olive-Purkinje cell pathway, the optic tectum, and the striatum, are known substrates for experience-dependent plasticity (Krupa and Thompson, 1997; Hyde and Knudsen, 2000; Doyon et al., 2003). This highlights the need for more studies investigating the role of ascending visual, auditory, and somatosensory information in complex learned motor skills such as birdsong and human speech.

In summary, our findings underscore the usefulness of the songbird system to study a gene implicated in human speech and language. FoxP2 has a characteristic expression pattern in a brain structure uniquely associated with learned vocal communication, Area $\mathrm{X}$ in songbirds. In the rest of the brain of birds that learn to sing and in birds that do not, FoxP2 expression predominates in sensory and sensory-motor circuits. These latter regions also express FoxP2 in mammals and reptiles. We conclude that FoxP2 may be important for establishing and maintaining brain pathways including, but not limited to, those essential for learned vocal communication.

\section{References}

Banham AH, Beasley N, Campo E, Fernandez PL, Fidler C, Gatter K, Jones M, Mason DY, Prime JE, Trougouboff P, Wood K, Cordell JL (2001) The FOXP1 winged helix transciption factor is a novel candidate tumor suppressor gene on chromosome 3p. Cancer Res 61:8820-8829.

Barami K, Iversen K, Furneaux H, Goldman SA (1995) Hu protein as an early marker of neuronal phenotypic differentiation by subependymal zone cells of the adult songbird forebrain. J Neurobiol 28:82-101.

Basham ME, Sohrabji F, Singh TD, Nordeen EJ, Nordeen KW (1999) Developmental regulation of NMDA receptor $2 \mathrm{~B}$ subunit mRNA and ifenprodil binding in the zebra finch anterior forebrain. J Neurobiol 39:155-167.

Belton E, Salmond CH, Watkins KE, Vargha-Khadem F, Gadian DG (2003) Bilateral brain abnormalities associated with dominantly inherited verbal and orofacial dyspraxia. Hum Brain Mapp 18:194-200.

Bentley GE, Spar BD, MacDougall-Shackleton SA, Hahn TP, Ball GF (2000) Photoperiodic regulation of the reproductive axis in male zebra finches, Taeniopygia guttata. Gen Comp Endocrinol 117:449-455.

Bottjer SW, Arnold AP (1985) Cerebral lateralization in birds. In: Cerebral lateralization in nonhuman species (Glick S, ed) , pp 11-38. Orlando, FL: Academic.

Bottjer SW, Johnson F (1997) Circuits, hormones and learning: vocal behavior in songbirds. J Neurobiol 33:602-618.

Brainard MS, Doupe AJ (2002) What songbirds teach us about learning. Nature 417:351-358.

Braun K, Scheich H, Schachner M, Heizmann CW (1985) Distribution of parvalbumin, cytochrome oxidase activity and 14C-2-deoxyglucose uptake in the zebra finch brain. Cell Tissue Res 240:101-115.

Braun K, Scheich H, Heizmann CW, Hunziker W (1991) Parvalbumin and calbindin-D28K immunoreactivity as developmental markers of auditory and vocal motor nuclei of the zebra finch. Neuroscience 40:853-869.

Brauth SE, Liang W, Roberts TF (2001) Projections of the oval nucleus of the hyperstriatum ventrale in the budgerigar: relationships with the auditory system. J Comp Neurol 432:481-511.

Bruce HA, Margolis RL (2002) FOXP2: novel exons, splice variants, and CAG repeat length stability. Hum Genet 111:136-144
Butler H, Juurlink BHJ (1987) An atlas for staging mammalian and chick embryos. Boca Raton, FL: CRC.

Carlsson P, Mahlapuu M (2002) Forkhead transcription factors: key players in development and metabolism. Dev Biol 250:1-23.

Csillag A (1999) Striato-telencephalic and striato-tegmental circuits: relevance to learning in domestic chicks. Behav Brain Res 98:227-236.

Doupe AJ, Kuhl PK (1999) Birdsong and human speech: common themes and mechanisms. Annu Rev Neurosci 22:567-631.

Doyon J, Penhune V, Ungerleider LG (2003) Distinct contribution of the cortico-striatal and cortico-cerebellar systems to motor skill learning. Neuropsychologia 41:252-262.

Durand SE, Heaton JT, Amateau SK, Brauth SE (1997) Vocal control pathways through the anterior forebrain of a parrot (Melopsittacus undulatus). J Comp Neurol 377:179-206.

Durbec P, Cremer H (2001) Revisiting the function of PSA-NCAM in the nervous system. Mol Neurobiol 24:53-64.

Enard W, Przeworski M, Fisher SE, Lai CS, Wiebe V, Kitano T, Monaco AP, Paabo S (2002) Molecular evolution of FOXP2, a gene involved in speech and language. Nature 418:869-872.

Evans S (2000) General discussion II: amniote evolution. Chichester, UK: Wiley.

Farries MA (2001) The oscine song system considered in the context of the avian brain: lessons learned from comparative neurobiology. Brain Behav Evol 58:80-100.

Farries MA, Perkel DJ (2002) A telencephalic nucleus essential for song learning contains neurons with physiological characteristics of both striatum and globus pallidus. J Neurosci 22:3776-3787.

Ferland RJ, Cherry TJ, Preware PO, Morrisey EE, Walsh CA (2003) Characterization of Foxp2 and Foxp1 mRNA and protein in the developing and mature brain. J Comp Neurol 460:266-279.

Fisher SE, Lai CS, Monaco AP (2003) Deciphering the genetic basis of speech and language disorders. Annu Rev Neurosci 26:57-80.

Hamburger V, Hamilton GS (1951) A series of normal stages in the development of the chick embryo. J Morphol 88:49-92.

Hanashima C, Li SC, Shen L, Lai E, Fishell G (2004) Foxg1 suppresses early cortical cell fate. Science 303:56-59.

Hemmings HC, Nairn AC, Bibb JA, Greengard P (1995) Signal transduction in the striatum: DARP32, a molecular integrator of multiple signaling pathways. In: Molecular and cellular mechanisms of neostriatal function (Ariano MA, Surmeier DJ, eds), pp 283-297. Heidelberg: Springer.

Holzenberger M, Jarvis ED, Chong C, Grossmann M, Nottebohm F, Scharff C (1997) Selective expression of insulin-like growth factor II in the songbird brain. J Neurosci 17:6974-6987.

Hyde PS, Knudsen EI (2000) Topographic projection from the optic tectum to the auditory space map in the inferior colliculus of the barn owl. J Comp Neurol 421:146-160.

Jarvis ED (2004) Brains and birdsong. In: Nature's music: the science of birdsong (Marler P, Slabbekoorn H, eds). Orlando, FL: Academic, in press.

Jarvis ED, Mello CV (2000) Molecular mapping of brain areas involved in parrot vocal communication. J Comp Neurol 419:1-31.

Jarvis ED, Schwabl H, Ribeiro S, Mello CV (1997) Brain gene regulation by territorial singing behavior in freely ranging songbirds. NeuroReport 8:2073-2077.

Jarvis ED, Ribeiro S, da Silva ML, Ventura D, Vielliard J, Mello CV (2000) Behaviourally driven gene expression reveals song nuclei in hummingbird brain. Nature 406:628-632.

Jarvis EJ, Nottebohm F (1997) Motor-driven gene expression. Proc Natl Acad Sci USA 94:4097-4102.

Kaestner KH, Knochel W, Martinez DE (2000) Unified nomenclature for the winged helix/forkhead transcription factors. Genes Dev 14:142-146.

Kaufmann E, Knochel W (1996) Five years on the wings of fork head. Mech Dev 57:3-20.

Krupa DJ, Thompson RF (1997) Reversible inactivation of the cerebellar interpositus nucleus completely prevents acquisition of the classically conditioned eye-blink response. Learn Mem 3:545-556.

Lai CS, Fisher SE, Hurst JA, Vargha-Khadem F, Monaco AP (2001) A forkhead-domain gene is mutated in a severe speech and language disorder. Nature 413:519-523.

Lai CS, Gerrelli D, Monaco AP, Fisher SE, Copp AJ (2003) FOXP2 expression during brain development coincides with adult sites of pathology in a severe speech and language disorder. Brain 126:2455-2462. 
Langham NPE (1987) The annual cycle of the avadavat Amandava amandava in Fidji. Emu 87:232-243.

Leitner S, Voigt C, Gahr M (2001) Seasonal changes in the song pattern of the non-domesticated canary (serinus canaria), a field study. Behaviour 138:885-904.

Lieberman P (2001) Human language and our reptilian brain. The subcortical bases of speech, syntax, and thought. Perspect Biol Med 44:32-51.

Li S, Weidenfeld J, Morrisey EE (2004) Transcriptional and DNA binding activity of the FoxP1/2/4 family is modulated by heterotypic and homotypic interactions. Mol Cell Biol 24:809-822.

Lu MM, Li S, Yang H, Morrisey EE (2002) FoxP4: a novel member of the Foxp subfamily of winged-helix genes co-expressed with Foxp1 and Foxp2 in pulmonary and gut tissues. Gene Expr Patterns 2:223-228.

Marcus GF, Fisher SE (2003) FOXP2 in focus: what can genes tell us about speech and language? Trends Cogn Sci 7:257-262.

Marien P, Engelborghs S, Fabbro F, De Deyn PP (2001) The lateralized linguistic cerebellum: a review and a new hypothesis. Brain Lang 79:580-600.

Medina L, Reiner A (1994) Distribution of choline acetyltransferase immunoreactivity in the pigeon brain. J Comp Neurol 342:497-537.

Mello CV, Jarvis ED, Denisenko N, Rivas M (1997) Differential display methods and protocols. In: Methods in molecular biology (Liang P, Pardee AB, eds), pp 205-217. Totowa, NJ: Humana.

Meyer A, Zardoya R (2003) Recent advances in the (molecular) phylogeny of vertebrates. Annu Rev Ecol Evol Syst 34:311-338.

Nottebohm F, Nottebohm ME, Crane L (1986) Developmental and seasonal changes in canary song and their relation to changes in the anatomy of song-control nuclei. Behav Neural Biol 46:445-471.

Parnavelas JG, Alifragis P, Nadarajah B (2002) The origin and migration of cortical neurons. Prog Brain Res 136:73-80.

Pinker S (1994) The language instinct. London: Lane.

Reiner A, Medina L, Veenman CL (1998) Structural and functional evolution of the basal ganglia in vertebrates. Brain Res Brain Res Rev 28:235-285.

Reiner A, Laverghetta AV, Meade CA, Cuthbertson SL, Bottjer SW (2004a) An immunohistochemical and pathway tracing study of the striatopallidal organization of Area X in the male zebra finch. J Comp Neurol 469:239-261.

Reiner A, Perkel DH, Bruce L, Butler AB, Csillag A, Kuenzel WJ, Medina L, Paxinos G, Shimizu T, Striedter GF, Wild JM, Ball GF, Durand SE, Güntürkün O, Lee D, Mello CV, Powers AS, White SA, Hough G, Kubicova L, Smulders TV, Wada K, Dugas-Ford J, Husband S, Yamamoto K, Yu J, Siang C, Jarvis ED (2004b) Revised nomenclature for avian telencephalon and some related brainstem nuclei. J Comp Neurol, in press.

Scharff C, Nottebohm F (1991) A comparative study of the behavioral deficits following lesions of various parts of the zebra finch song system: implications for vocal learning. J Neurosci 11:2896-2913.

Seiler HW, Gahr M, Goldsmith AR, Guttinger HR (1992) Prolactin and gonadal steroids during the reproductive cycle of the Bengalese finch (Lonchura striata var. domestica, Estrildidae), a nonseasonal breeder with biparental care. Gen Comp Endocrinol 88:83-90.

Shu W, Yang H, Zhang L, Lu MM, Morrisey EE (2001) Characterization of a new subfamily of winged-helix/forkhead (Fox) genes that are expressed in the lung and act as transcriptional repressors. J Biol Chem 276:27488-27497.

Sibley CG, Ahlquist JE (1990) Phylogeny and classification of birds: a study in molecular evolution. New Haven, CT: Yale UP.
Singh TD, Heinrich JE, Wissman AM, Brenowitz EA, Nordeen EJ, Nordeen KW (2003) Seasonal regulation of NMDA receptor NR2B mRNA in the adult canary song system. J Neurobiol 54:593-603.

Smith GT, Brenowitz EA, Beecher MD, Wingfield JC (1997) Seasonal changes in testosterone, neural attributes of song control nuclei, and song structure in wild songbirds. J Neurosci 17:6001-6010.

Smith S (1991) The black-capped chickadee: behavioral ecology and natural history. Cornell, NY: Cornell UP.

Snyder GL, Fienberg AA, Huganir RL, Greengard P (1998) A dopamine/D1 receptor/protein kinase A/dopamine- and cAMP-regulated phosphoprotein $(\mathrm{Mr} 32 \mathrm{kDa}) /$ protein phosphatase-1 pathway regulates dephosphorylation of the NMDA receptor. J Neurosci 18:10297-10303.

Sohrabji F, Nordeen EJ, Nordeen KW (1990) Selective impairment of song learning following lesions of a forebrain nucleus in the juvenile zebra finch. Behav Neural Biol 53:51-63.

Staden R, Beal KF, Bonfield JK (1998) The Staden package. Methods Mol Biol 132:115-130.

Striedter GF (1994) The vocal control pathways in budgerigars differ from those in songbirds. J Comp Neurol 343:35-56.

Takahashi K, Liu FC, Hirokawa K, Takahashi H (2003) Expression of Foxp2, a gene involved in speech and language, in the developing and adult striatum. J Neurosci Res 73:61-72.

Tchernichovski O, Mitra PP, Lints T, Nottebohm F, Ho CE, Pesaran B (2001) Dynamics of the vocal imitation process: how a zebra finch learns its song. A procedure for an automated measurement of song similarity. Science 291:2564-2569.

Teramitsu I, Kudo LC, London SE, Geschwind DH, White SA (2004) Parallel FoxP1 and FoxP2 expression in songbird and human brain predicts functional interaction. J Neurosci 24:3152-3163.

Vargha-Khadem F, Watkins K, Alcock K, Fletcher P, Passingham R (1995) Praxic and nonverbal cognitive deficits in a large family with a genetically transmitted speech and language disorder. Proc Natl Acad Sci USA 92:930-933.

Vortkamp A, Lee K, Lanske B, Segre GV, Kronenberg HM, Tabin CJ (1996) Regulation of rate of cartilage differentiation by Indian hedgehog and PTH-related protein. Science 273:613-622.

Wada K, Sakaguchi H, Jarvis ED, Hagiwara M (2004) Specialized neural transmitter receptor expression for learned vocal communication. J Comp Neurol, in press.

Watkins KE, Gadian DG, Vargha-Khadem F (1999) Functional and structural brain abnormalities associated with a genetic disorder of speech and language. Am J Hum Genet 65:1215-1221.

Watkins KE, Dronkers NF, Vargha-Khadem F (2002) Behavioural analysis of an inherited speech and language disorder: comparison with acquired aphasia. Brain 125:452-464.

Wilbrecht L, Nottebohm F (2003) Vocal learning in birds and humans. Ment Retard Dev Disabil Res Rev 9:135-148.

Wild JM, Williams MN, Suthers RA (2001) Parvalbumin-positive projection neurons characterize the vocal premotor pathway. Brain Res 917:235-252.

Zann RA (1996) The zebra finch: a synthesis of field and laboratory studies. New York: Oxford UP.

Zhang J, Webb DM, Podlaha O (2002) Accelerated protein evolution and origins of human-specific features. Foxp2 as an example. Genetics 162: 1825-1835. 